\title{
Ecological and microbiological diversity of chigger mites, including vectors of scrub typhus, on small mammals across stratified habitats in Thailand
}

Kittipong Chaisiri ${ }^{1,2}$, A. Christina Gill ${ }^{1,3}$, Alexandr A. Stekolnikov ${ }^{4}$, Soawapak Hinjoy ${ }^{5}$, John W. McGarry ${ }^{6}$, Alistair C. Darby ${ }^{7}$, Serge Morand ${ }^{8}$ and Benjamin L. Makepeace ${ }^{1 *}$ (D)

\begin{abstract}
Background: Scrub typhus, caused by a bacterial pathogen (Orientia spp.), is a potentially life-threatening febrile illness widely distributed in the Asia-Pacific region and is emerging elsewhere. The infection is transmitted by the larval stage of trombiculid mites ("chiggers") that often exhibit low host specificity. Here, we present an analysis of chigger ecology for 38 species sampled from 11 provinces of Thailand and microbiomes for eight widespread species.

Results: In total, > 16,000 individual chiggers were collected from 1574 small mammal specimens belonging to 18 species across four horizontally-stratified habitat types. Chigger species richness was positively associated with higher latitudes, dry seasonal conditions, and host maturity; but negatively associated with increased human land use. Human scrub typhus incidence was found to be positively correlated with chigger species richness. The bacterial microbiome of chiggers was highly diverse, with Sphingobium, Mycobacterium, Neisseriaceae and various Bacillales representing the most abundant taxa. Only Leptotrombidium deliense was found to be infected with Orientia and another potential pathogen, Borrelia spp., was frequently detected in pools of this species. $\beta$-diversity, but not a-diversity, was significantly different between chigger species and geographic regions, although not between habitat types.

Conclusion: Our study identified several key environmental and host-derived correlates of chigger species richness across Thailand, which in turn impacted on human scrub typhus incidence. Moreover, this first extensive field survey of the chigger microbiome revealed species- and province-level variation in microbial $\beta$-diversity across the country, providing a framework for future studies on interactions between pathogens and other symbionts in these understudied vectors.
\end{abstract}

\section{Background}

The Trombiculoidea is a superfamily of mites (Acari: Acariformes) with a unique mode of parasitism among medically-relevant arthropod vectors. The larval stage, colloquially known as chiggers or berry bugs, is ectoparasitic on vertebrates (or occasionally invertebrates). In contrast, the deutonymph and adult stages have an edaphic lifestyle and are free-living predators of arthropods or their eggs [1]. Chiggers are the exclusive biological vectors of scrub typhus, a potentially life-threatening febrile

\footnotetext{
* Correspondence: blm1@liverpool.ac.uk

${ }^{1}$ Institute of Infection \& Global Health, University of Liverpool, Liverpool, UK Full list of author information is available at the end of the article
}

illness of humans that historically has been associated only with the Asia-Pacific region [2]. However, recently endemic scrub typhus has been reported from the Middle East [3] and South America [4], and local transmission is suspected in sub-Saharan Africa [5]. The main aetiological agent of the disease, Orientia tsutsugamushi (Rickettsiales: Rickettsiaceae), is a vertically-transmitted chigger symbiont that has been reported to induce reproductive manipulations in its arthropod host [6].

The epidemiology of scrub typhus remains poorly understood, largely because chiggers are minute (typically $<250 \mu \mathrm{m}$ in length) and very challenging to identify and utilise for molecular characterisation and screening [7]. In particular, interactions between climatic and 
physical geography, wild vertebrate hosts, and human disturbance of the environment with chigger species richness and abundance, and how these variables impact on scrub typhus incidence, are largely unexplored in most endemic regions. Moreover, our understanding of the bacterial associates of chiggers is mainly restricted to $O$. tsutsugamushi and a very small number of other potential human pathogens, such as Bartonella spp. [8] and Rickettsia spp. [9]. As many cases of epidemiological-relevant interactions between human pathogens and the microbiome of arthropod vectors have been reported, our ignorance regarding the chigger microbiome is of potential concern for disease control. Indeed, this was highlighted recently by a $16 \mathrm{~S}$ rRNA amplicon survey of a colony of the scrub typhus vector Leptotrombidium imphalum, which revealed a hitherto unrecognised association between a novel member of the Amoebophilaceae and $O$. tsutsugamushi in adult female mites [10]. The completion of the Leptotrombidium deliense genome project also uncovered an intimate relationship between chiggers and soil bacteria and fungi, as genes for secondary metabolism have been acquired by lateral transfer from these microorganisms [11].

Among scrub typhus-endemic countries, Thailand has some of the highest incidence rates. The Thai Bureau of Epidemiology reported an increase in annual minimum incidence from 6.0 per 100,000 persons in 2003 to 17.1 per 100,000 in 2013 [2]. The role of the vector in this increase is unknown, but the higher prevalence of $O$. tsutsugamushi in small mammal chigger hosts from forested regions relative to areas with greater human disturbance implicates land use as a key factor in disease risk [12]. Interestingly, provinces at higher latitudes in Thailand have elevated incidence rates of scrub typhus compared with other parts of the country, as well as the greatest chigger species diversity [13]. We therefore hypothesized that chigger species richness may be a driver of scrub typhus incidence across the whole country, perhaps by facilitating recombination between $O$. tsutsugamushi strains [14]. In addition, since the chigger genome has been shaped by contact with soil microorganisms [11], we tested the hypothesis that the chigger microbiome is strongly influenced by local habitat type. This is important, as in other arthropod vectors, intracellular bacterial symbionts and gut microbiota are known to have significant impacts on vector competence [15-17].

Here, we present an analysis of chigger distributions on small mammals across 11 provinces of Thailand, their associations with habitat types stratified by human disturbance, and the microbiomes of eight widelydistributed chigger species. We show that chigger species richness is influenced by mammalian host status, climatic factors and land use; whereas chigger species and geographic region, although not habitat type, significantly affect the $\beta$-diversity of chigger microbiomes.

\section{Results \\ Chigger ecology and host associations}

A total of 16,761 chiggers were obtained from 1574 small mammals belonging to 18 species (Additional file 1). The overall infestation rate was $23.8 \%$, with Bo Kleu district (Nan province) displaying the highest rate recorded for a single site (95\%) (Additional file 2: Table S1). The highest mean chigger intensity (113.3) was observed in Berylmys bowersi (Bower's white-toothed rat) (Additional file 2: Table S2). A subsample of 2519 chiggers (approximately $15 \%$ of the total) were identified to the species level, revealing that Rattus tanezumi (Asian house rat) and Bandicota indica (greater bandicoot rat) exhibited the greatest chigger species richness (21 species each). Approximately half of the infested hosts (50.7\%) harboured a single chigger species, $33.3 \%$ harboured two, and the remainder harboured $\geq 3$ species. Ascoshoengastia indica was most prevalent (7.31\%; the only species recorded from every geographic region), followed by L. deliense (5.22\%) and Walchia micropelta (5.16\%) (Additional file 2: Table S3).

A species accumulation curve plot demonstrated that the sample size of small mammals was sufficient to describe the chigger species diversity accurately, since a plateau was reached at around 1000 hosts (Additional file 2: Figure S1). Chigger species richness of sampling locations increased at higher latitudes (Spearman's rank correlation $=60.81, p=0.0023$; Additional file 2: Figure S2) and varied significantly among the four habitat types (in descending order) of forest, dryland, rain-fed land, and human settlement at both an individual host level (Kruskal-Wallis statistic $=91.29, \mathrm{df}=3, p<0.0001$; Fig. $1 \mathrm{~b}$ ) and for the whole population (Fig. 1a). Moreover, while there were no seasonal differences in chigger species richness or abundance at the individual host level, chigger species richness was considerably higher in the dry season than in the wet season at the whole country level (Fig. 1c). Ecological specialisation of some of the most widespread chigger species (A. indica, W. micropelta and Walchia pingue) between habitat types was weak (Fig. 2). However, $L$. deliense showed a preference for areas in forest or dryland; whereas other species with more restricted distributions displayed predilections for human settlements (Helenicula kohlsi), rain-fed lowland (e.g., Walchia minuscuta, Shoengastiella ligula and Blankaartia acuscutellaris) or dry landscapes (Helenicula pilosa) (Fig. 2).

Bipartite network analysis showed highly complex interactions between chigger and host species (Fig. 3a). The largest chigger species assemblages at the whole host population level were found on two rodent species associated with human settlements and lowland agriculture, 

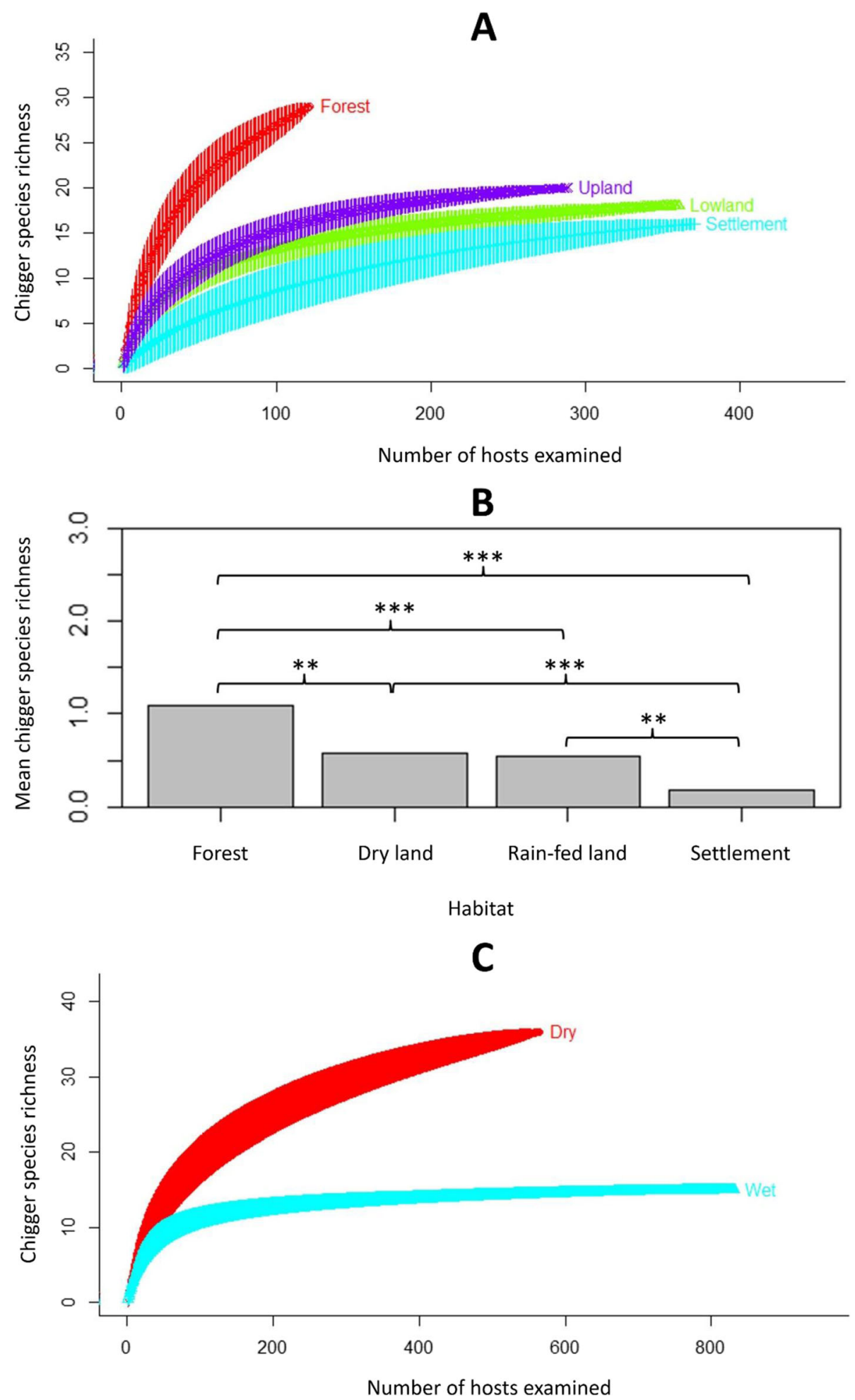

Fig. 1 Effect of habitat and season on chigger species richness. a Chigger species accumulation curves among different habitats at the host population level. b Mean chigger species richness per host individual by habitat type. c Chigger species accumulation curves between the dry (red) and wet (blue) season 


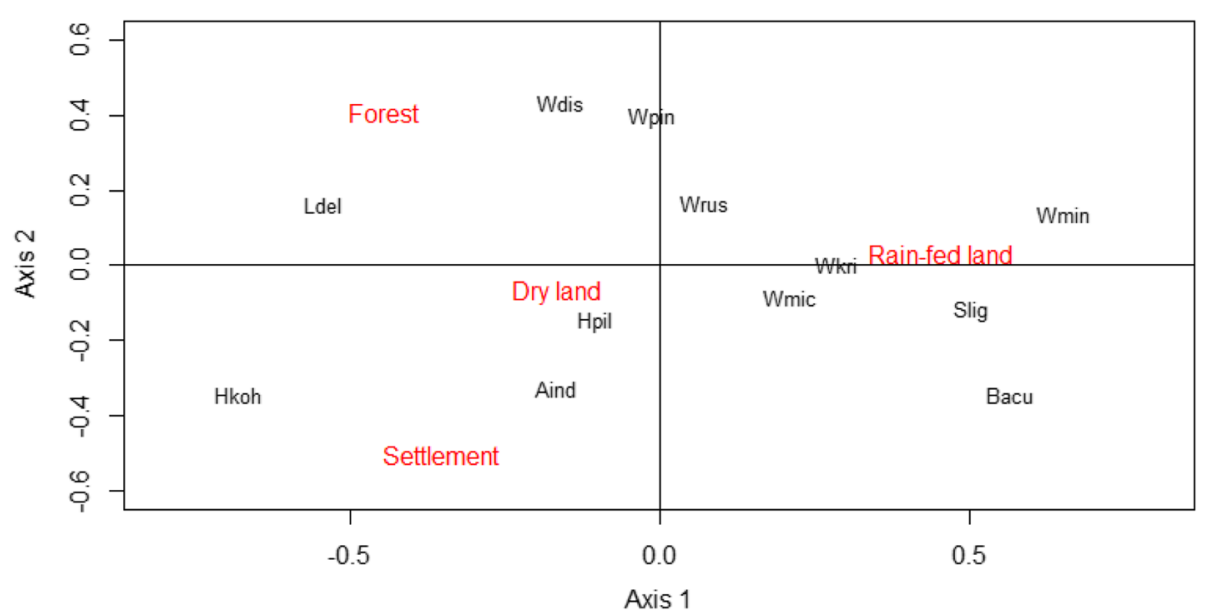

Fig. 2 Correspondence analysis showing the association between the 12 dominant chigger species (Aind, Ascoschoengastia indica; Bacu, Blankaartia acuscutellaris; Hkoh, Helenicula kohlsi; Hpil, Helenicula pilosa; Ldel, Leptotrombidium deliense; Slig, Schoengastiella ligula; Wdis, Walchia dismina; Wkri, Walchia kritochaeta; Wmic, Walchia micropelta; Wmin, Walchia minuscuta; Wpin, Walchia pingue; Wrus, Walchia rustica) within the four categorized habitats. The first and second dimensions explain $87 \%$ of the total variance (axis 1, 59.82\%; axis 2, 27.38\%)

$B$. indica and $R$. tanezumi. Interestingly, the only nonrodent hosts sampled in this study, Hylomys suillus (Erinaceomorpha: Erinaceidae) and Tupaia glis (Scandentia: Tupaiidae), were parasitized by several chigger species never found on rodents (Fig. 3a). Overall however, more than half of chigger species were found on more than one host species, and the species-specificity for those found on $>10$ individual animals was only $0.171-0.542$. A unipartite network analysis supported the bipartite analysis, assigning $B$. indica and $R$. tanezumi with the highest Eigenvector centrality scores among all of the hosts (Fig. 3b).

\section{Chigger-host properties and scrub typhus incidence}

For each of the 13 geographic sites, bipartite network properties of host-chigger interactions were calculated at the individual host level, including the nestedness metric based on overlap and decreasing fill (NODF), network connectance, links per species, and network modularity. The highest NODF and connectance were found in the Nakhonsawan network, where chigger species richness was only four species; while the Chiangrai network exhibited an elevated chigger species richness (12 species), but with the lowest NODF and connectance (Additional file 2: Table S4). In contrast, Chiangrai displayed the highest modularity within the network, whereas the least network modularity was found in Prachuab Kirikhan (Additional file 2: Table S4).

We tested the effect of various independent variables on individual chigger species richness using GLMs with model selection by Akaike's Information Criterion. Host species, host maturity, site and habitat (but not host sex) were significant variables in the best 10 models (Additional file 2: Table S5; Figure S3a). Animals captured in forest demonstrated significantly higher chigger species richness than hosts from human settlements (estimate $=-1.074$, $p<0.0001$; Additional file 2: Table S6), and species richness was greater on mature hosts than on juveniles (estimate $=-0.283, p=0.004$; Additional file 2: Table S6).

We then applied the same modelling approach but included human scrub typhus cases at district level with environmental variables (elevation, annual mean temperature and latitude; Additional file 2: Table S7), chigger species richness, and network properties (Additional file 2: Figure S3b). Network connectance and chigger species richness strongly influenced local scrub typhus case numbers, as the two variables appeared in the top 10 selected models (Additional file 2: Table S8). Finally, we performed a univariate analysis, which also showed that scrub typhus case number was positively correlated with chigger species richness (Spearman rank correlation $=45.71, p=0.0006$; Fig. 4a) and negatively correlated with host-chigger network connectance (Spearman's rank correlation $=485.45$, $p=0.011$; Fig. 4b). Importantly, there was no significant relationship between overall chigger abundance and scrub typhus incidence $\left(\mathrm{R}^{2}=0.105, P=0.732\right.$; data not shown).

\section{Microbiome of individual and pooled chigger specimens}

The total number of 16S rRNA reads from the complete set of 366 samples (264 individual chiggers, 69 pooled chiggers, 18 soil samples and 15 background controls) after quality filtering, de-multiplexing and error correction was $51,896,654$ (mean reads per sample $=137,657$; $\mathrm{SD}=69,522$ ). After paired read alignment and size selection at $270-300 \mathrm{bp}$, the read number was $49,635,427$ ( mean reads per sample $=131,659 ; \mathrm{SD}=69,922)$, a sequence retention of $94 \%$. The analysis of individual chigger specimens comprised nine widespread species: A. indica, L. deliense, W. micropelta, W. minuscuta, 

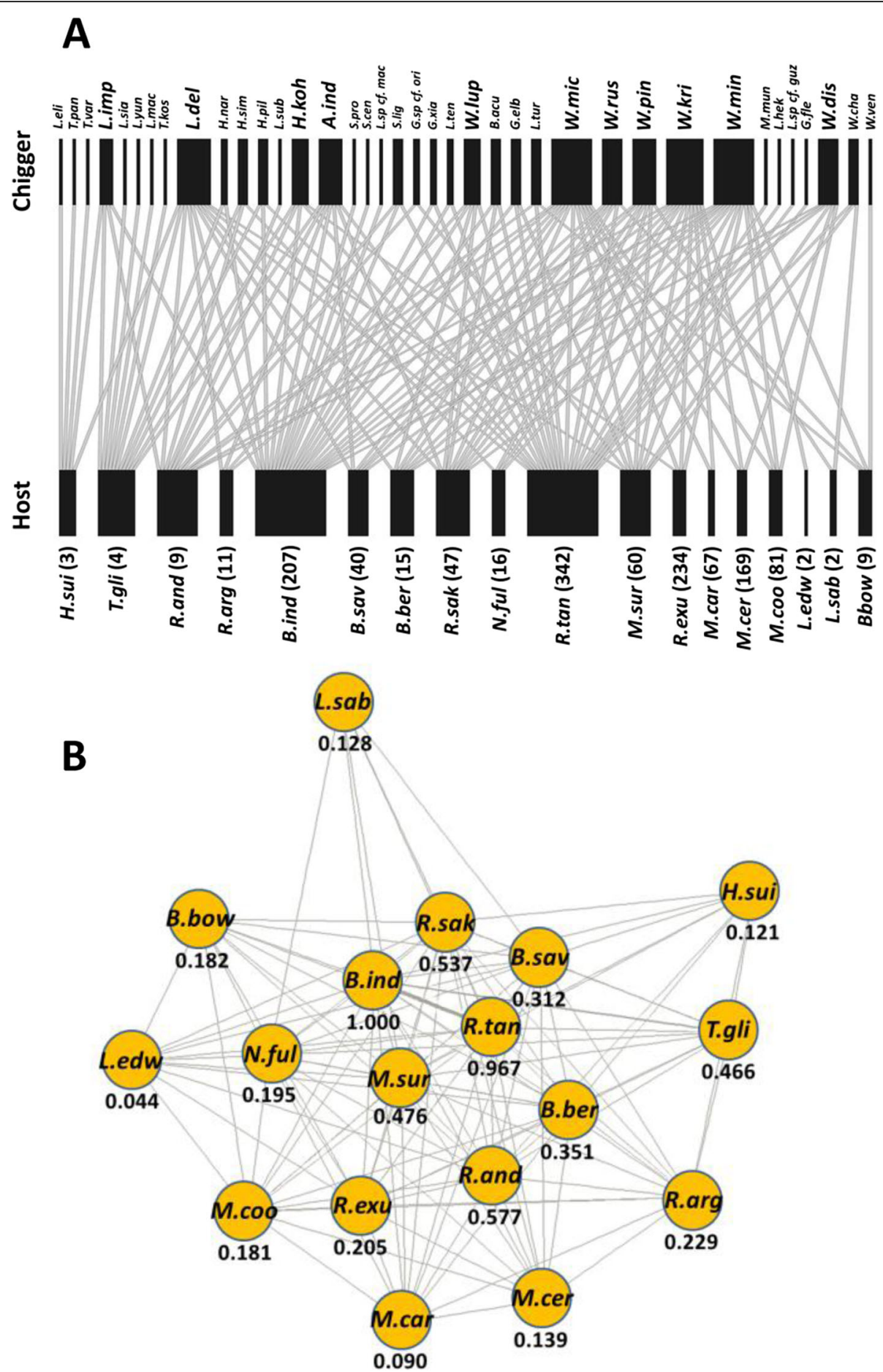

Fig. 3 Host-chigger associations in Thailand. a Bipartite graph based on presence-absence data. The number of individual hosts examined is shown in parentheses. Chigger species with broad host ranges are displayed in bold. b Unipartite network and Eigenvector centrality scores illustrating the pattern of chigger sharing among 18 small mammal hosts

Walchia kritochaeta, H. pilosa, H. kohlsi, B. acuscutellaris, and S. ligula. However, after removing samples with high similarity to negative controls (see Additional file 2: Supplementary Methods), more than half (58.7\%) were excluded from downstream analyses, including all of those for $W$. minuscuta. After several steps of additional data quality filtering; i.e., removal of predicted chimeric sequences, filtering of OTUs at $>1 \%$ relative 
A

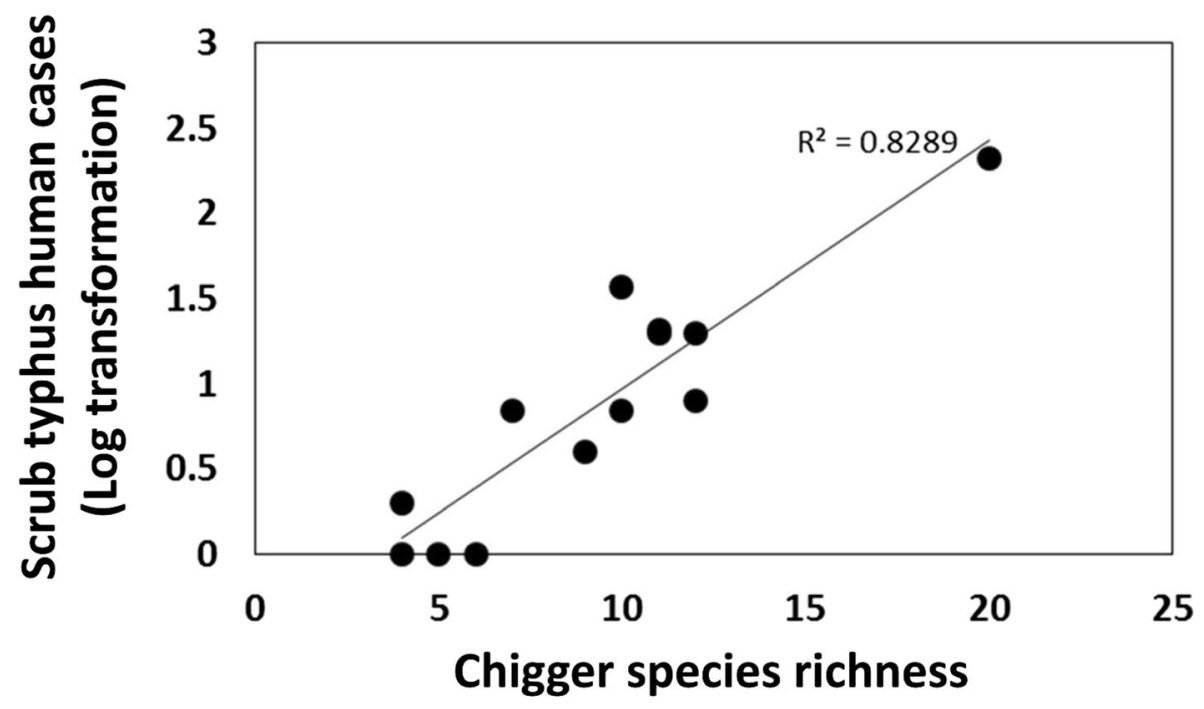

B

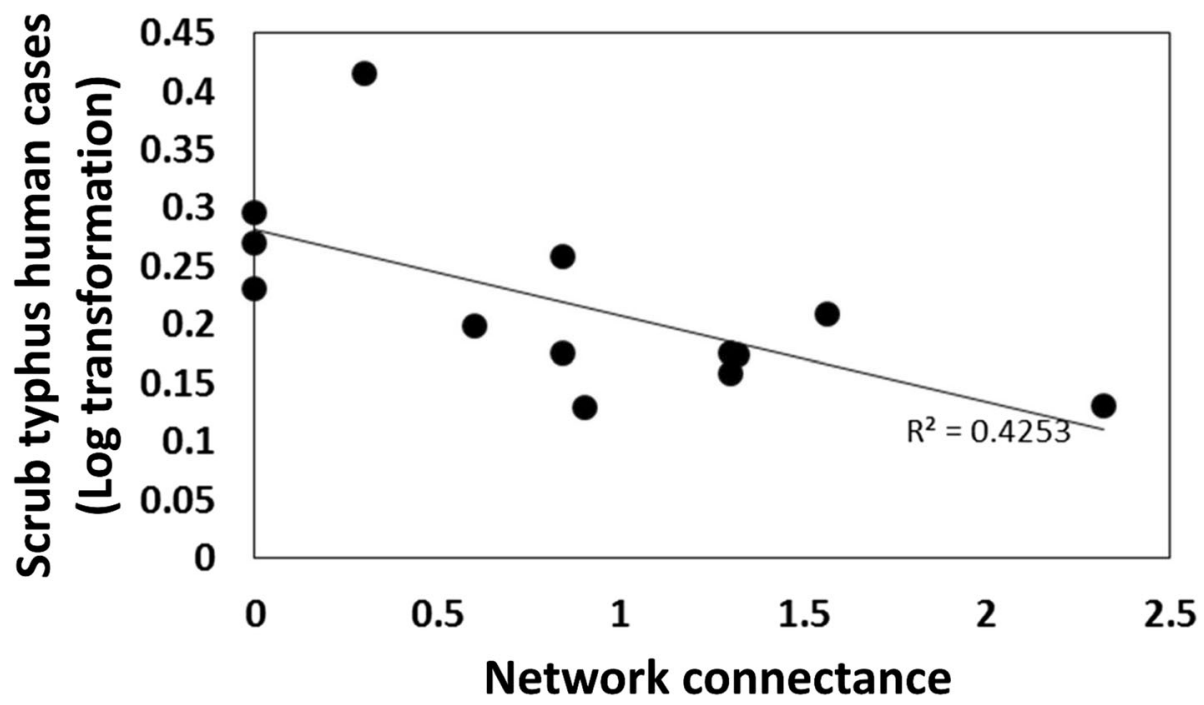

Fig. 4 Correlation plots show the relationship between chigger ecology [(a) chigger species richness; (b) host-chigger network connectance] and scrub typhus incidence in humans. Incidence data are displayed as the $\log _{10}$ transformation of the number of cases per year

abundance, and removal of OTUs with $<5$ reads, 817 OTUs (Additional file 3) were identified from 207 retained samples with a total of 21,696,826 reads.

The microbiomes of individual chiggers were dominated by several different Geobacillus OTUs (Fig. 5). However, Sphingobium ( $\alpha$-Proteobacteria) was also abundant, as were Comamonadaceae (especially in Walchia spp.) and Brevibacillus (particularly in B. acuscutellaris and $L$. deliense). Importantly, we only detected $O$. tsutsugamushi in $L$. deliense (3/39 individual specimens that passed QC), with a maximum OTU proportion of $19.58 \%$ (Fig. 5; Table 1). Other bacteria with pathogenic potential in humans were found across several chigger species, including Mycobacterium (11.93\% of specimens), Staphylococcus (8.25\%) and Haemophilus parainfluenzae (7.34\%) (Table 1). However, most arthropod symbionts known to be of importance in other mite species or in insects (Cardinium, Pseudonocardia and Rickettsiella) were rare $(<2 \%$ prevalence), while Wolbachia remained undetected at the individual level (Table 1).

To mitigate the problem of low biomass when amplifying $16 \mathrm{~S}$ rRNA fragments from individual chiggers, we also sequenced several pools of 50 specimens each for $A$. indica, $L$. deliense, W. micropelta, W. minuscuta, and $B$. 


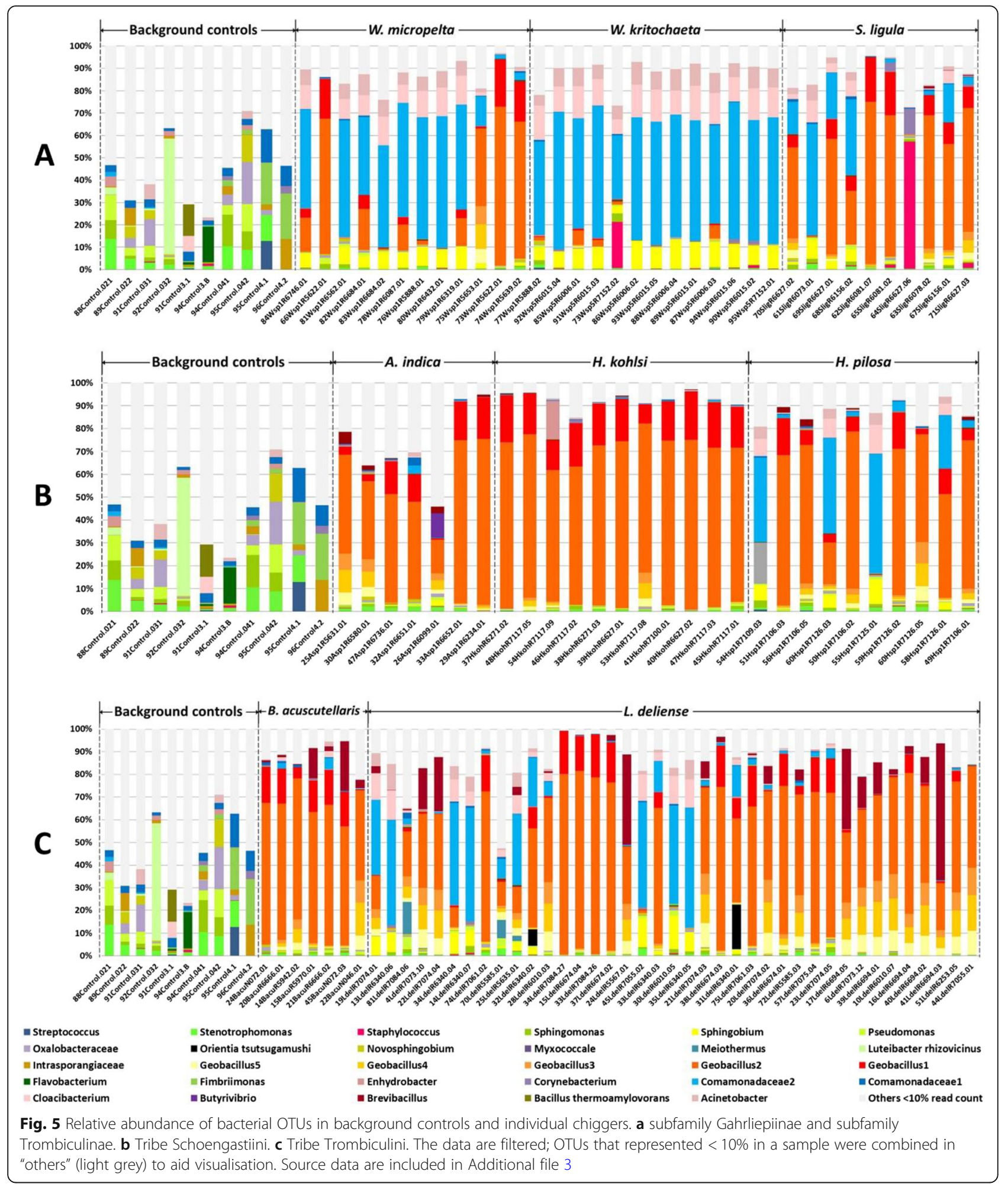

acuscutellaris (Fig. 6a); as well as three mixed-species pools of 50 specimens each for all 11 Thai provinces (Fig. 6b). This strategy was successful, as fewer samples (7.2\%) were removed due to high similarity with negative controls when compared with individual samples. Surprisingly, two
OTUs (Geobacillus and Brevibacillus) that were highly prevalent and relatively abundant in the individual-level data were not present at a read count $\geq 5$ in any of the pooled data (Table 1). For some of the potential pathogens, individual and pooled data showed good concordance 
Table 1 Selected bacterial taxa of public health importance, potential symbionts, and other prevalent OTUs detected in individual and pooled chiggers in comparison to soils and background controls

\begin{tabular}{|c|c|c|c|c|c|}
\hline \multirow[t]{2}{*}{ Bacterial taxa (OTU identifier) } & \multirow{2}{*}{$\begin{array}{l}\text { Maximum OTU } \\
\text { Proportion (\%) }\end{array}$} & Individual chigger & \multirow{2}{*}{$\begin{array}{l}\text { Pooled chigger } \\
\text { Positive samples(\%) }\end{array}$} & \multirow{2}{*}{$\begin{array}{l}\text { Soil } \\
\text { Positive samples (\%) }\end{array}$} & \multirow{2}{*}{$\begin{array}{l}\text { Control } \\
\text { Positive samples (\%) }\end{array}$} \\
\hline & & Positive samples (\%) & & & \\
\hline \multicolumn{6}{|l|}{ Opportunistic/Potential pathogens } \\
\hline Bacillus cereus (4463224) & $1.63^{\mathrm{P}}$ & $4(3.67)$ & $31(47.69)$ & $11(61.11)$ & - \\
\hline Borrelia (New.ReferenceOTU7) & $34.82^{P}$ & $1(0.92)$ & $32(49.23)$ & - & - \\
\hline $\begin{array}{l}\text { Campylobacter } \\
\text { (New.CleanUp.ReferenceOTU30) }\end{array}$ & $1.49^{\mathrm{P}}$ & - & $3(4.62)$ & - & - \\
\hline Clostridium (New.ReferenceOTU2470) & $3.43^{\mathrm{P}}$ & - & $6(9.23)$ & - & - \\
\hline Corynebacterium (13485) & $16.36^{\mathrm{P}}$ & $7(6.42)$ & $65(100)$ & - & $2(13.33)$ \\
\hline Fusobacterium (2438396) & $2.44^{\mathrm{P}}$ & $1(0.92)$ & $6(9.23)$ & - & - \\
\hline Haemophilus parainfluenzae (4473129) & $1.83^{1}$ & $8(7.34)$ & $17(26.15)$ & - & $1(6.67)$ \\
\hline Moraxella (1127280) & $1.63^{\mathrm{P}}$ & - & $4(6.15)$ & - & - \\
\hline Mycobacterium (4448095) & $5.22^{\mathrm{P}}$ & 13(11.93) & $48(73.85)$ & $18(100)$ & - \\
\hline Nocardia (102163) & $17.41^{P}$ & $5(4.58)$ & $35(53.84)$ & $1(5.55)$ & - \\
\hline Orientia tsutsugamushi (301131) & $19.57^{\prime}$ & $3(2.75)$ & $13(20)$ & - & - \\
\hline Staphylococcus (4446058) & $55.99^{1}$ & $67(61.47)$ & $65(100)$ & $3(16.66)$ & $6(40)$ \\
\hline \multicolumn{6}{|l|}{ Potential arthropod symbionts } \\
\hline $\begin{array}{l}\text { Candidatus Cardinium } \\
\text { (New.ReferenceOTU10) }\end{array}$ & $19.06^{P}$ & $2(1.83)$ & 18(27.69) & - & - \\
\hline Neisseriaceae (933546) & $92.48^{\mathrm{P}}$ & $18(16.51)$ & $62(95.38)$ & $5(27.78)$ & $4(26.67)$ \\
\hline Rickettsiella (8028) & $1.12^{\mathrm{P}}$ & $2(1.83)$ & $12(18.46)$ & - & - \\
\hline Wolbachia (New.ReferenceOTU2936) & $2.32^{\mathrm{P}}$ & - & $2(3.08)$ & - & - \\
\hline \multicolumn{6}{|l|}{ Other prevalent OTUs } \\
\hline Acinetobacter rhizosphaerae (4334053) & $6.13^{\mathrm{P}}$ & $4(3.67)$ & $33(50.77)$ & - & - \\
\hline Brevibacillus (3307468) & $60.37^{\prime}$ & $61(55.96)$ & - & - & - \\
\hline Burkholderia bryophila (4320353) & $1.27^{1}$ & $38(34.86)$ & $2(3.07)$ & - & - \\
\hline Geobacillus (New.ReferenceOTU5884) & $10.73^{\prime}$ & $82(75.23)$ & - & - & - \\
\hline Nevskia (516554) & $2.06^{1}$ & $27(24.77)$ & $3(4.61)$ & 7(38.88) & - \\
\hline Sphingobacterium multivorum (4423201) & $1.16^{1}$ & $44(40.36)$ & $15(23.07)$ & - & $1(6.67)$ \\
\hline Sphingobium (4393057) & $14.69^{\prime}$ & $82(75.23)$ & $11(16.92)$ & $1(5.55)$ & - \\
\hline Streptomyces (821185) & $59.26^{1}$ & $2(1.83)$ & 13(20) & $1(5.55)$ & - \\
\hline Methylobacterium adhaesivum (4303249) & $3.96^{1}$ & $11(10.09)$ & $12(18.46)$ & - & - \\
\hline
\end{tabular}

Only the OTUs with $\geq 5$ reads were included. Superscript "I" or "P" indicate maximum OTU proportion values from individual or pooled chiggers, respectively. For source data and representative sequences, see Additional file 3

(Staphylococcus and Mycobacterium detected in 95.38 and $73.85 \%$ of pools, respectively), whereas others that were rarely detected in individuals were robustly confirmed by the pooling strategy (Borrelia in $49.23 \%$ and Corynebacterium in $78.46 \%$ of pools, respectively) (Table 1 ). Indeed, a pool of L. deliense from dryland habitats revealed a maximum OTU proportion of $34.82 \%$ for a Borrelia sp. (Table 1). Pooling also provided additional evidence that three classical arthropod symbionts (Cardinium, Pseudonocardia and Rickettsiella) were present in chiggers $(\sim 20-45 \%$ of pools), while a fourth (Wolbachia) was present only in two (3.08\%) pools (Table 1). One Neisseriaceae OTU (933546) was detected in $95.38 \%$ of pooled samples and was particularly dominant in L. deliense, reaching a maximum OTU proportion of $92.48 \%$ (Table 1). In accordance with the individual chigger data, the $13(20 \%)$ pooled samples positive for O. tsutsugamushi (Table 1) all contained $L$. deliense.

To investigate whether the presence of Geobacillus might have resulted from contamination of samples with spores in the laboratory or with bacterial DNA in the extraction kits, we first examined OTUs sequenced from negative controls, then measured levels of Firmicutes $16 \mathrm{~S}$ rDNA by qPCR in chiggers compared with samples from the laboratory water bath. The dominant Geobacillus OTU observed in individual chiggers was absent in 


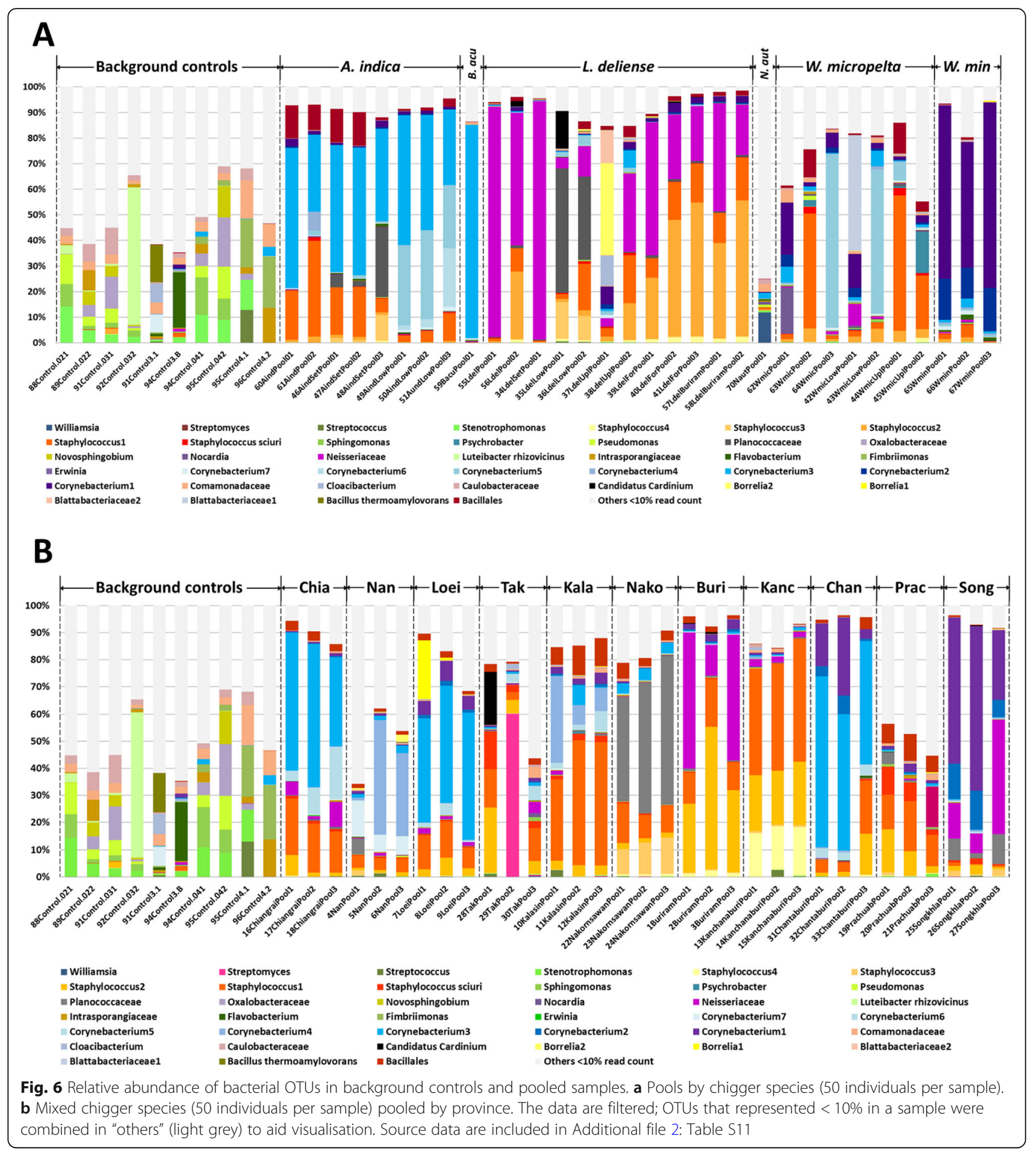

background controls (Table 1; Additional file 2: Table S9). Despite a high Firmicutes signal in the water bath (Additional file 2: Figure S4), Sanger sequencing revealed that this was derived from Paenibacillus spp. and related Bacillales, whereas Geobacillus spp. were only observed in individual chigger samples (Additional file 2: Figure S5; Additional file 4). Finally, we calculated percent GC content for the 15 most abundant OTUs in individual specimens and the 26 most abundant OTUs in pooled samples. This showed that the GC content of the OTUs from individual specimens was significantly higher than for the pooled material $(P=0.0094$; Additional file 2: Figure $S 6)$.

\section{Factors affecting the microbial profile of chiggers}

The $\alpha$-diversity of bacterial OTUs determined by a richness estimator (Chao1) and the whole-tree phylogenetic 
diversity index (PD_whole_tree) revealed significant differences between the sample types, with pooled chigger and soil samples exhibiting higher diversity than individual chigger specimens (Kruskal-Wallis test with post-hoc Bonferroni correction, $P<0.001$ ) (Additional file 2: Table S10). The latter were not significantly more diverse than control samples. Analysis of $\beta$-diversity showed that the sample types were generally well separated from one another (ANOSIM: $R=0.7997, P=0.001$ ), although some background controls were nested on the periphery of the individual chigger samples (Additional file 2: Figure S7). Bacterial communities were significantly clustered with respect to chigger species and geographic location (study sites) in both individual and pooled chiggers $(P<0.001)$, whereas habitat (human disturbance transect) failed to show a significant effect (Fig. 7). The impact of chigger species and geographic location on $\beta$-diversity displayed similar correlation coefficients and network topology (Fig. 7).

\section{Discussion}

To the best of our knowledge, habitat type, chigger diversity and human scrub typhus incidence have never been analysed together on a countrywide scale before. The current study sampled more than one-third of known chigger species in Thailand [13] and found three significant environmental associations with species richness: a positive correlation with latitude, a negative correlation with increased human land use, and an elevated level of chigger diversity in the dry season (in addition to significant effects of host species and maturity). Latitudinal gradients are associated with bioclimatic factors such as mean temperature, humidity and rainfall, and the species richness of animals and plants tends to increase at lower latitudes approaching the equator [1820]. Thus, parasite diversity might also be expected to be higher at lower latitudes, and there is some evidence of this for microbial pathogens [21-23]. However, the opposite trend observed here is supported by previous studies on fleas [24]. Moreover, in Yunnan province in China, chigger diversity on small mammals was even higher than in our study and increased according to latitude up to a zenith at $25-26^{\circ} \mathrm{N}$ before decreasing further north [25], suggesting the presence of an optimum zone (our study covered $7-19^{\circ} \mathrm{N}$ ). One hypothesis to explain this phenomenon is that the geographic range of individual hosts tends to be broader at higher latitudes, perhaps facilitating the accumulation of a greater diversity of ectoparasites [20].

Analysis of chigger distributions in Yunnan also concur with our findings on the impact of human disturbance of the natural environment, with a significantly greater host and chigger species richness being observed in a mountainous uncultivated landscape habitat compared with a cultivated flatland landscape [26]. We increased the resolution of the human land use analysis in our study by trapping hosts across a transect of four rather than two habitat categories, which revealed a stepwise reduction in chigger species richness as human disturbance increased, reflecting the universal process of loss of animal and plant diversity through urbanisation. Seasonality was also an apparent determinant of chigger diversity in our study, with a striking increase in species richness during the dry season compared with the wet season. However, caution is required in interpreting this finding, as our field studies were not designed to standardise sampling across the two seasons. Nevertheless, it is plausible that breeding frequency is reduced in the wet season, and/or that many chiggers emerging from underground during monsoon periods are washed into water bodies before they can attach to a host. Chigger species also have different seasonal preferences. For instance, in subtropical regions, most scrub typhus cases occur in the autumn when populations of Leptotrombidium pallidum and Leptotrombidium scutellare dramatically increase (as seen in South Korea [27, 28]), or the main vector may change between summer and winter (as seen with $L$. deliense and L. scutellare in Taiwan, respectively [29]).

Here, the species richness of chiggers was identified as a positive correlate of scrub typhus incidence for the first time. Since decreased human land use is associated with both increased chigger species richness (this study) and higher prevalence of $O$. tsutsugamushi infection in small mammals [12], increased biodiversity may be a risk factor for human scrub typhus. This contradicts a metaanalysis of chigger-host relationships in Yunnan, where a lower host and chigger diversity in cultivated flatland was associated with a greater abundance of chiggers, especially species that are known or potential vectors of scrub typhus [26]. However, as neither human scrub typhus incidence nor $O$. tsutsugamushi prevalence in small mammals was incorporated into the Yunnan study, and an efficient scrub typhus vector (L. scutellare) was abundant in mountainous uncultivated land (the higher biodiversity site), the impact of land use on infection risk remains an open question in that region. In Taiwan, spatial modelling of land use data revealed significant positive correlations between crop-vegetation mosaics and forest, as well as elevation, with scrub typhus incidence [30]. In contrast with our study, follow-up investigations in Taiwan found that chigger prevalence and abundance on small mammals was positively associated with both human scrub typhus incidence and host $O$. tsutsugamushi seropositivity [29]. Chigger species richness and host-chigger networks were not explicitly incorporated into this Taiwanese study, but both the diversity of chiggers (12 species) and their hosts (8 species) were markedly lower than we observed in Thailand. 


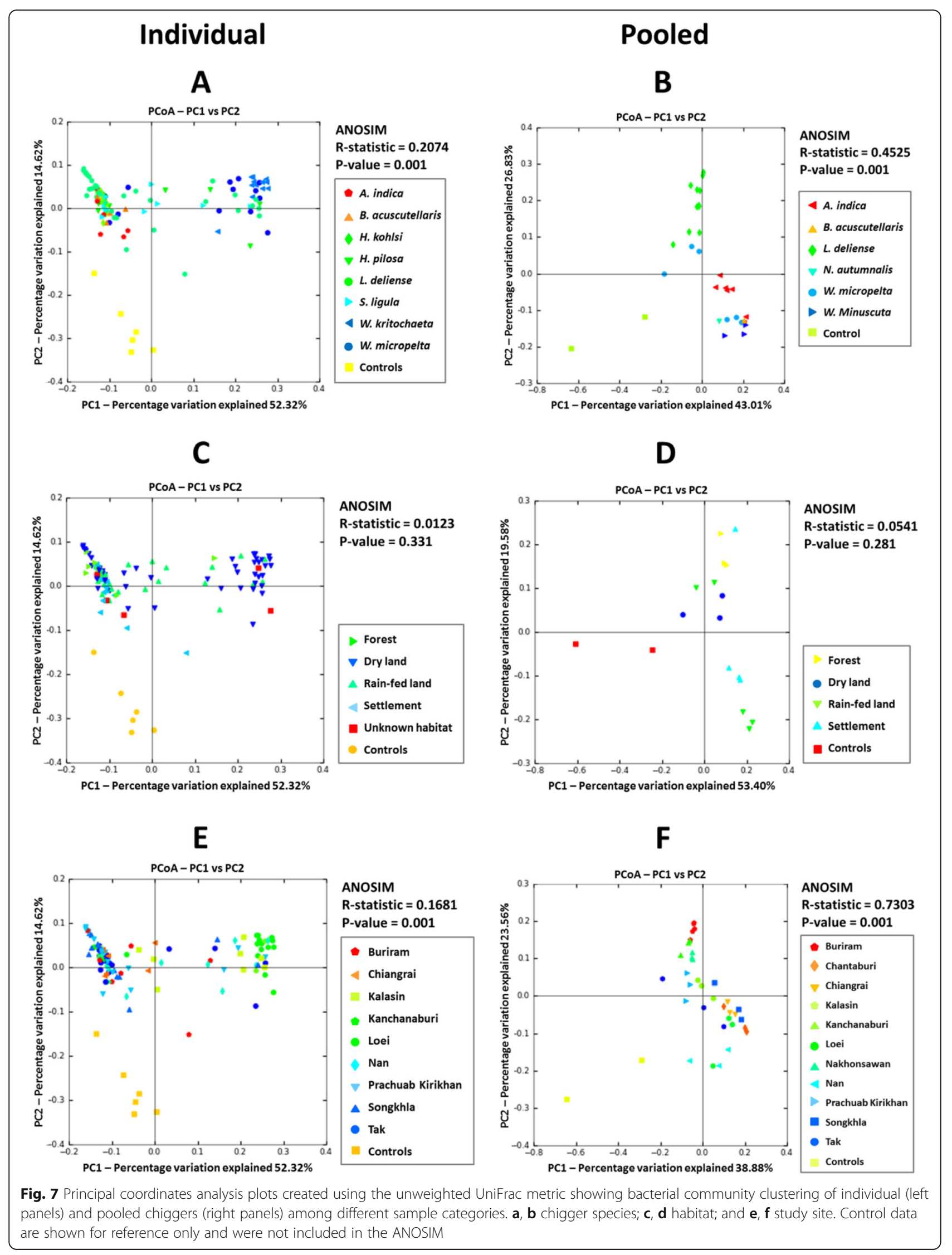


At first glance, the association between chigger species richness and scrub typhus incidence in Thailand seems paradoxical as we only detected $O$. tsutsugamushi in a single species (L. deliense). Yet it is important to emphasise that other potential vectors of scrub typhus (e.g., $L$. imphalum, the principal vector in northern Thailand [31]) were collected but not subjected to $16 \mathrm{~S}$ rRNA sequencing. Moreover, more than 20 species of Leptotrombidium have been reported from Thailand, many only from the northern provinces where scrub typhus incidence is highest [13]. Although the majority of these species are not known to be scrub typhus vectors, recent data on vector competence are lacking, and it is plausible that transmission of $O$. tsutsugamushi by two or more vectors in the same region may contribute to diversification of the pathogen and an increase in human cases, as has been recently hypothesised for Taiwan [14, 29]. We also observed that human scrub typhus incidence was negatively associated with host-parasite network connectance, suggesting that increasing complexity of chigger-host interactions might reduce human exposure by zooprophylaxis, or lead to a greater likelihood that non-vector species dominate networks.

With the exception of a laboratory colony of L. imphalum [10], the composition of the chigger microbiome was largely unknown prior to our study. Our data reveal complex microbiomes that (in contrast with those of many other arthropods such as certain vectors [32] or sap-feeding insects [33]) are not dominated by a very small number of specialised primary and secondary symbionts. Since questing chiggers emerge from underground and are associated with their host for only few days before moulting into free-living nymphs, we hypothesised that they may not require symbionts for dietary supplementation, and may passively accumulate soil microbes instead. Indeed, it is now known that the L. deliense genome contains terpene synthase genes that appear to have been acquired by ancient lateral gene transfer from Actinobacteria and other environmental phyla [11]. However, while bacterial sequences of putative soil origin were prevalent in chiggers (e.g., Bacillus cereus and Mycobacterium spp.), on the basis of the limited number of soil samples we analysed here, the chigger "microbiome" is not simply a result of soil particles adhering to the mite surface. The clear impact of chigger species and geographical location, but not human land disturbance, on the microbial sequence profiles lends further support to the concept of an integral microbiome in chiggers that may be modulated by habitat on large (several hundred $\mathrm{km}$ ) but not small (a few $\mathrm{km}$ ) scales. This may be because their mobile hosts can travel between the human disturbance zones we defined within sampling sites [34, 35]. Evidence that the host also contributes to the chigger microbiome was revealed by the presence of typical mammalian-associated flora such as Staphylococcus spp. and Haemophilus spp.

The prevalence of the classical intracellular arthropod symbionts Cardinium, Rickettsiella and Wolbachia was quite low in individual specimens, despite their importance in other mite taxa [36]. While Orientia in some Leptotrombidium spp. could conceivably displace these symbionts due to competition for intracellular niches, it is rare or absent in most other chigger genera [37]. Unfortunately, the sample size of Orientia-infected chiggers was too small in this study to investigate the impact of the pathogen on microbiome composition. In contrast to a recent analysis of the microbiome of colonised $L$. imphalum, we found no evidence for an abundant Amoebophilaceae OTU; although this is not surprising, as it was found to be uncommon in all life stages except Orientia-infected adult females [10], and neither this species nor life stage was included in our microbiome analysis. Future studies should consider the role of Neisseriaceae OTU 933546 in chigger biology and potential interactions with vectored pathogens. Notably, this family in the $\beta$-proteobacteria exhibited a moderate prevalence in $L$. deliense individuals and contains gut symbionts of bees (Snodgrassella alvi [38]) and termites (Stenoxybacter acetivorans [39]). This suggests a facultative relationship in $L$. deliense because OTU 933546 was also found in almost $30 \%$ of soil samples. The presence of Borrelia spp. in $L$. deliense is also noteworthy, especially as the prevalence of this potential pathogen was much higher than observed in European chigger species, where only a fraction of $1 \%$ of individuals appear to be infected with Lyme disease spirochetes [40, 41]. To the best of our knowledge, Borrelia spp. have not been identified in chiggers from South-East Asia previously, and L. deliense deserves further consideration as a potential vector.

The high prevalence of sequences from Geobacillus spp. was surprising, since this is a thermophilic, sporeforming genus with an optimal growth range of 45$70{ }^{\circ} \mathrm{C}$. Geobacillus spp. thrive in hot composts, subterranean oilfields and hydrothermal vents, but due to their exceedingly robust spores that can be transported worldwide in atmospheric currents, isolates have been obtained across a vast range of temperate or cold terrestrial and marine sediments [42]. We did not surface-sterilise the chiggers as there is little evidence this procedure significantly affects microbiome data obtained from arthropods [43], and the risk of degradation of internal DNA when dealing with soft, minute species that might exhibit small breaches in their exoskeleton was acute. Moreover, this procedure can remove potential OTUs of interest, such as vertebrate pathogens transmitted in arthropod faeces [44] or ectosymbionts on the cuticle surface $[45,46]$ that may have important biological roles. In any case, the dominant Geobacillus OTU detected in individual chiggers was 
absent from the soil we analysed. Despite the potential ubiquity of Geobacillus spp. spores in the environment, it is intriguing that this genus is not observed more frequently in arthropod microbiomes. In addition to aphids [47] and ants [48], Geobacillus spp. sequences have been reported from sandflies [49], mosquitoes [50] and ticks [51]. In mosquitoes, Geobacillus spp. were identified as part of the core microbiome of dissected reproductive tracts [50]; whereas in the tick Dermacentor occidentalis, it was associated with a greater abundance of Francisella relative to Rickettsia [51]. These findings indicate that although the genus Geobacillus is assumed to be exclusively thermophilic, it may have a potential biological role in disease vectors, suggesting that some strains may actually be mesophilic.

The high prevalence of Geobacillus sequences in our individual, but not pooled, chigger data raised important questions about both reagent contamination with bacterial DNA and amplification biases caused by variation in GC content. Several recent studies have highlighted the pitfalls of microbiome studies on low biomass samples, where bacterial DNA present in molecular biology reagents competes very effectively as PCR template with bacterial DNA from the sample itself [52, 53]. Since DNA from more than 180 environmental bacterial genera has been detected in commercially available DNA extraction kits [53], assessing the true impact of laboratory contamination on the ensuing data is extremely challenging. The conservative approach that we used here for the individual chiggers was effective but led to exclusion of more than half of these samples from downstream analyses.

Pooling appears to be an obvious solution to the problem of low biomass samples [54], but is not without its own drawbacks. Genomic GC content is now well known as a source of bias in $16 \mathrm{~S}$ rRNA datasets, with higher GC content leading to underrepresentation [55], as we observed here with Geobacillus spp. (relatively high median GC of $~ 52 \%$ ) in pooled samples. At lower template concentrations, denaturation of DNA appears to have been more efficient, revealing OTUs that would have remained hidden had we only sequenced pools.

\section{Conclusion}

This study emphasises that among human disease vectors, chiggers exhibit some of the most complex ecological relationships [56], with high species diversity and low host specificity contributing to elevated rates of coinfection on individual mammalian hosts. The diverse microbiomes of chiggers add a further layer to the network of potential interactions that Orientia is exposed to, and future studies should determine whether some of these commensal bacteria affect chigger vector competence. Moreover, the positive correlation we identified here between chigger species richness and scrub typhus incidence deserves further investigation in other endemic countries, especially in relation to the epidemiology of Orientia strain diversity [14].

\section{Methods}

For a more detailed description of the Methods, see Additional file 2: Supplementary Methods.

\section{Trapping of small mammals and chigger collections}

This study utilised chigger material collected previously for a taxonomic study in Thailand [13]. In brief, small mammals were trapped across 13 localities between 2008 and 2015, once each in the dry season and wet season. Chiggers were removed from mammal cadavers and fixed in 70-95\% ethanol. Mites collected from each animal were counted to determine mean infestation intensity and mean chigger abundance on different host species, as defined by Rózsa et al. [57]. For identification and species richness estimation, $10-20 \%$ of chiggers from each host animal were selected using size and microscopic appearance as a guide to obtain a representative sub-sample. They were mounted in Berlese's fluid for morphological identification and retained as voucher specimens.

\section{Ecological analysis}

For ecological analysis, trapping sites were divided equally into four different types of habitats with respect to human land use (anthropization index), spanning low to high levels of disturbance $[35,58,59]$. Calculation of chigger diversity estimations [chigger species richness and chigger diversity index (Shannon's index)] were performed using the "BiodiversityR" package. In addition, 12 chigger species that infested $\geq 10$ individual hosts were included in an analysis of association with habitat type using the "FactoMineR" package in $\mathrm{R}$.

\section{Network analyses of host-chigger interactions}

To study the community ecology of host-chigger interactions, bipartite network analyses of host-ectoparasite interactions were conducted at both community (pooled host species or pooled locations) and individual levels using "vegan" [60] and "bipartite" packages [61] implemented in $\mathrm{R}$ freeware. Bipartite networks were transformed to unipartite networks using the "tnet" package [62]. Unipartite network plots illustrate relative interaction patterns within a host community with respect to the co-occurrence of chigger species.

\section{Multiple regression models of independent variables explaining chigger species richness}

Generalized linear models were constructed in order to identify potential effects of host attributes (species, sex, maturity and body mass) and ecological factors (habitat, 
site and season) on chigger species richness at the individual host level. Poisson regression models were created for chigger species richness count data using the "Ime4" package [63] in $\mathrm{R}$ freeware. Selection of models was based on Akaike's Information Criterion adjusted for small sample size (AICc) using the "gmulti" package [64] in $\mathrm{R}$ freeware. Data for scrub typhus human case numbers from the 13 studied sites were obtained from the Bureau of Epidemiology, Ministry of Public Health, Thailand (unpublished data).

\section{DNA extraction}

As clearing in Berlese's fluid destroys DNA, chiggers destined for DNA extraction followed a different workflow to the voucher specimens and were identified using autofluorescence microscopy as previously described [7]. Genomic DNA was purified using the DNeasy Blood \& Tissue Kit (Qiagen, Hilden, Germany).

\section{Library preparation and next generation sequencing of 16S rRNA amplicons}

To determine the bacterial microbiome of chiggers, a dual-index nested PCR protocol for MiSeq (Illumina, San Diego, CA, USA) sequencing was applied [65-67] targeting the v4 region of the $16 \mathrm{~S}$ rRNA gene. The second round indexing PCR was performed using the Nextera XT DNA protocol (Illumina). Each MiSeq run included three types of negative control to identify potential background contamination from sample manipulation equipment, DNA extraction kits and PCR reagents used in library preparation. Samples were submitted for sequencing with $300 \mathrm{bp}$ paired-end chemistry on the Illumina MiSeq platform at the Centre for Genomic Research (University of Liverpool). The trimmed and de-multiplexed reads were submitted to the Sequence Read Archive at the National Center for Biotechnology Information under study number PRJNA576374.

\section{Microbiome profiling}

Analyses of $16 \mathrm{~S}$ rRNA microbiome profile were performed using the Quantitative Insights into Microbial Ecology (QIIME) software package, version 1.8.0 [68]. The OTUs were created using an open-reference approach using the USEARCH61 method [69] whereby reads are binned at 97\% similarity [69] against the Greengene database v. 13_8 [70] followed by de novo OTU picking. Bacterial taxonomic assignment was performed with UCLUST. Chimeric sequences were removed using "ChimeraSlayer" [71].

\section{Comparative analyses of the chigger microbiome}

Read counts were normalized to relative abundance for graphing or rarefied to 10,000 reads for diversity calculations. Bacterial communities were categorised according to sample type (individuals and pools), selected chigger species and study sites (mixed species), as well as soil samples from Thailand and Lao PDR. For details of $\alpha-$ and $\beta$-diversity analyses, and principal coordinates analysis (PCoA), see Supplemental Materials and Methods.

\section{Geobacillus qPCR and sanger sequencing}

A pair of PCR primers (sense: GTCCGGAATTATTG GGCGTA; antisense: TACGCATTTCACCGCTACAC) was designed to amplify a $16 \mathrm{~S}$ rRNA gene portion for the genus Geobacillus and related Firmicutes. Individual, 25pooled and 50-pooled chiggers, as well as water samples from the laboratory water bath (Grant Sub; Grant Instruments, Cambridge, UK) and Qiagen microbial DNA-free water (negative control), were used in the qPCR assay. DNA from chiggers and $10 \mu \mathrm{l}$ of water bath samples were extracted using the DNeasy Blood \& Tissue Kit (Qiagen).

Bacterial taxonomy was assigned using RDP Classifier Version 2.10 [72] available at https://rdp.cme.msu.edu, using a $>80 \%$ confidence threshold [73]. The DNA sequences were aligned using ClustalW and phylogenetic tree construction was performed with the maximum likelihood method using Mega software version 6.06 [74].

\section{Determination of GC content in 16S rRNA sequences}

We evaluated whether the influence of GC content differentially affected data obtained from individual and pooled chiggers (low and high DNA concentration templates, respectively). Representative sequences of the dominant bacterial OTUs from individual and pooled chiggers were assessed for GC content using "Oligo Calc", an oligonucleotide properties calculator available at http://biotools. nubic.northwestern.edu/OligoCalc.html [75] and their mean GC content was compared by two-sample $t$-test.

\section{Supplementary information}

Supplementary information accompanies this paper at https://doi.org/10. 1186/s42523-019-0019-x.

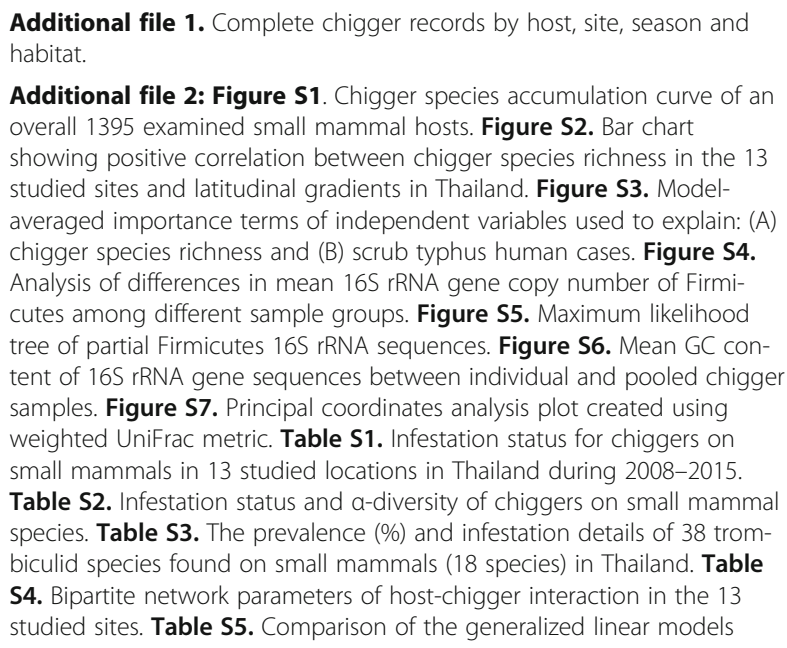

Additional file 2: Figure S1. Chigger species accumulation curve of an overall 1395 examined small mammal hosts. Figure S2. Bar chart showing positive correlation between chigger species richness in the 13 studied sites and latitudinal gradients in Thailand. Figure S3. Modelaveraged importance terms of independent variables used to explain: (A) chigger species richness and (B) scrub typhus human cases. Figure S4. Analysis of differences in mean $16 \mathrm{~S}$ rRNA gene copy number of Firmicutes among different sample groups. Figure S5. Maximum likelihood tree of partial Firmicutes 165 rRNA sequences. Figure S6. Mean GC content of 165 rRNA gene sequences between individual and pooled chigger samples. Figure S7. Principal coordinates analysis plot created using weighted UniFrac metric. Table S1. Infestation status for chiggers on small mammals in 13 studied locations in Thailand during 2008-2015. Table S2. Infestation status and a-diversity of chiggers on small mammal species. Table S3. The prevalence (\%) and infestation details of 38 trombiculid species found on small mammals (18 species) in Thailand. Table S4. Bipartite network parameters of host-chigger interaction in the 13 studied sites. Table S5. Comparison of the generalized linear models 
(GLM) testing the effect of various independent variables on individual chigger species richness (GLM with Poisson distribution). Table S6. Generalized linear models of individual chigger species richness (with Poisson distribution). Table S7. Human scrub typhus case number and environmental information at the district level for the 13 studied sites. Table S8. Comparison of the general linear models (GLM) to test the effect of various independent variables to scrub typhus human case number (GLM with Poisson distribution). Table S9. The 34 dominant OTUs (more than $5 \%$ proportional read count in a single control) present in background controls. Table S10. a-diversity estimation of bacterial OTUs among sample groups and categories. Supplementary Materials and Methods. Supplementary References.

Additional file 3. Complete OTU dataset for chiggers, soil samples and background controls by read count and proportion; representative sequences for each OTU are also included.

Additional file 4. Sequences obtained from a gPCR targeting Firmicutes DNA in chigger, laboratory water bath and negative control samples (see Additional file 2: Figure S5 for details).

\section{Abbreviations}

NODF: Nestedness metric based on overlap and decreasing fill;

OTU: Operational taxonomic unit; PCoA: Principal coordinates analysis; QIIME: Quantitative Insights into Microbial Ecology

\section{Acknowledgments}

We thank Sabine Dittrich (Lao-Oxford-Mahosot Hospital Wellcome Trust Research Unit) for supplying soil samples from Laos and Xiaofeng Dong (University of Liverpool) for bioinformatic support.

\section{Authors' contributions}

The study was designed by KC, BLM and SM. Fieldwork was conducted by KC and SM. Chigger identification was performed by KC, JWM and AAS. Ecological analyses were conducted by KC and SM. Molecular laboratory procedures were performed by KC. Bioinformatics and microbiome analyses were undertaken by KC, ACG and ACD. Unpublished human scrub incidence data were provided by SH. The manuscript was drafted by BLM, KC and ACG; and all authors read and approved the final draft.

\section{Funding}

The lead author (KC) was supported by the Mahidol-Liverpool Chamlong Harinasuta PhD Scholarship scheme. Field studies were funded by French Agence Nationale de la Recherche grants ANR-07-BDIV-012 ("CERoPath") and ANR-11-CPEL-002 ("BiodivHealthSEA") projects to SM, who was also supported by the award "FutureHealthSEA" (ANR-17-CE35-0003).

\section{Availability of data and materials}

Data generated or analysed during this study are included in this published article and its supplementary information files. Raw sequence data have been submitted to the Sequence Read Archive under study number PRJNA576374

\section{Ethics approval and consent to participate}

None of the small mammal species investigated are on the Convention on International Trade in Endangered Species of Wild Fauna and Flora (CITES) list, nor the International Union for Conservation of Nature Red List. Animals were treated in accordance with the guidelines of the American Society of Mammalogists, and with the European Union legislation (Directive 86/609/ EEC). The ANR-SEST (Agence Nationale pour la Recherche, Santé-Environnement et Santé-Travail) programme on rodent-borne diseases in Southeast Asia, which provided part of the funding for this project, was approved by the Managing Directors from both the Thai and French research institutes. In addition, approval was obtained from the regional Head of Veterinary Service (Hérault, France) for the sampling and killing of rodents (approval no. B 34169-1) carried out during this study.

\section{Consent for publication}

Not applicable.

\section{Competing interests}

None.

\section{Author details}

${ }^{1}$ Institute of Infection \& Global Health, University of Liverpool, Liverpool, UK

${ }^{2}$ Faculty of Tropical Medicine, Mahidol University, Bangkok, Thailand.

${ }^{3}$ Biomedical Services, University of Oxford, Oxford, UK. ${ }^{4}$ Zoological Institute, Russian Academy of Sciences, Saint Petersburg, Russia. ${ }^{5}$ Department of Disease Control, Ministry of Public Health, Nonthaburi, Thailand. ${ }^{6}$ Institute of Veterinary Science, University of Liverpool, Liverpool, UK. 'Institute of Integrative Biology, University of Liverpool, Liverpool, UK. ${ }^{8}$ Faculty of Veterinary Technology, Kasetsart University, Bangkok, Thailand.

Received: 8 May 2019 Accepted: 20 November 2019 Published online: 05 December 2019

\section{References}

1. Shatrov AB, Kudryashova NI. Taxonomy, life cycles and the origin of parasitism in trombiculid mites. In: Morand S, Krasnov BR, Poulin R, editors. Micromammals and Macroparasites: From Evolutionary Ecology to Management. Tokyo: Springer Japan; 2006. p. 119-40.

2. Bonell A, Lubell Y, Newton PN, Crump JA, Paris DH. Estimating the burden of scrub typhus: a systematic review. PLoS Negl Trop Dis. 2017;11:e0005838. https://doi.org/10.1371/journal.pntd.0005838.

3. Izzard L, Fuller A, Blacksell SD, Paris DH, Richards AL, Aukkanit N, et al. Isolation of a novel Orientia species (O. chuto sp. nov.) from a patient infected in Dubai. J Clin Microbiol. 2010;48:4404-9. https://doi.org/10.1128/ JCM.01526-10

4. Weitzel T, Dittrich S, Lopez J, Phuklia W, Martinez-Valdebenito C, Velasquez K, et al. Endemic scrub typhus in South America. N Engl J Med. 2016;375: 954-61. https://doi.org/10.1056/NEJMoa1603657.

5. Masakhwe C, Linsuwanon P, Kimita G, Mutai B, Leepitakrat S, Yalwala S, et al. Identification and characterization of Orientia chuto in trombiculid chigger mites collected from wild rodents in Kenya. J Clin Microbiol. 2018;56. https://doi.org/10.1128/JCM.01124-18.

6. Takahashi M, Urakami H, Yoshida Y, Furuya Y, Misumi H, Hori E, et al. Occurrence of high ratio of males after introduction of minocycline in a colony of Leptotrombidium fletcheri infected with Orientia tsutsugamushi. Eur J Epidemiol. 1997;13:79-86.

7. Kumlert R, Chaisiri K, Anantatat T, Stekolnikov AA, Morand S, Prasartvit A, et al. Autofluorescence microscopy for paired-matched morphological and molecular identification of individual chigger mites (Acari: Trombiculidae), the vectors of scrub typhus. PLoS One. 2018;13:e0193163. https://doi.org/10. 1371/journal.pone.0193163.

8. Kabeya H, Colborn JM, Bai Y, Lerdthusnee K, Richardson JH, Maruyama S, et al. Detection of Bartonella tamiae DNA in ectoparasites from rodents in Thailand and their sequence similarity with bacterial cultures from Thai patients. Vect-Borne Zoon Dis. 2010;10:429-34

9. Huang Y, Zhao L, Zhang Z, Liu M, Xue Z, Ma D, et al. Detection of a novel Rickettsia from Leptotrombidium scutellare mites (Acari: Trombiculidae) from Shandong of China. J Med Entomol. 2017;54:544-9. https://doi.org/10.1093/ jme/tjw234.

10. Ponnusamy L, Willcox AC, Roe RM, Davidson SA, Linsuwanon P, Schuster AL, et al. Bacterial microbiome of the chigger mite Leptotrombidium imphalum varies by life stage and infection with the scrub typhus pathogen Orientia tsutsugamushi. PLoS One. 2018;13:e0208327. https://doi.org/10.1371/journal. pone.0208327.

11. Dong X, Chaisiri K, Xia D, Armstrong SD, Fang Y, Donnelly MJ, et al. Genomes of trombidid mites reveal novel predicted allergens and laterally transferred genes associated with secondary metabolism. Gigascience. 2018; 7:giy127. https://doi.org/10.1093/gigascience/giy127.

12. Chaisiri K, Cosson JF, Morand S. Infection of rodents by Orientia tsutsugamushi, the agent of scrub typhus in relation to land use in Thailand. Trop Med Infect Dis. 2017;2. https://doi.org/10.3390/tropicalmed2040053.

13. Chaisiri K, Stekolnikov AA, Makepeace BL, Morand S. A revised checklist of chigger mites (Acari: Trombiculidae) from Thailand, with the description of three new species. J Med Entomol. 2016;53:321-42. https://doi.org/10.1093/jme/tjv244.

14. Kim G, Ha NY, Min CK, Kim HI, Yen NT, Lee KH, et al. Diversification of Orientia tsutsugamushi genotypes by intragenic recombination and their potential expansion in endemic areas. PLoS Negl Trop Dis. 2017;11: e0005408. https://doi.org/10.1371/journal.pntd.0005408.

15. Macaluso KR, Sonenshine DE, Ceraul SM, Azad AF. Rickettsial infection in Dermacentor variabilis (Acari: Ixodidae) inhibits transovarial transmission of a second Rickettsia. J Med Entomol. 2002;39:809-13. 
16. Zele F, Nicot A, Duron O, Rivero A. Infection with Wolbachia protects mosquitoes against Plasmodium-induced mortality in a natural system. J Evol Biol. 2012;25:1243-52. https://doi.org/10.1111/j.1420-9101.2012.02519.x.

17. Narasimhan S, Rajeevan N, Liu L, Zhao YO, Heisig J, Pan J, et al. Gut microbiota of the tick vector Ixodes scapularis modulate colonization of the Lyme disease spirochete. Cell Host Microbe. 2014;15:58-71. https://doi.org/ 10.1016/j.chom.2013.12.001

18. Lindenfors $P$, Nunn $C L$, Jones $K E$, Cunningham $A A$, Sechrest W, Gittleman JL. Parasite species richness in carnivores: effects of host body mass, latitude, geographical range and population density. Glob Ecol Biogeogr. 2007;16: 496-509.

19. Bordes F, Morand S, Krasnov BR, Poulin R. Parasite diversity and latitudinal gradients in terrestrial mammals. In: Morand S, Krasnov BR, editors. The Biogeography of Host-Parasite Interactions. New York: Oxford University Press; 2010. p. 89-98.

20. Morand S. (macro-) evolutionary ecology of parasite diversity: from determinants of parasite species richness to host diversification. Int J Parasitol Parasites Wildl. 2015;4:80-7. https://doi.org/10.1016/j.ijppaw.2015.01.001.

21. Guernier V, Hochberg ME, Guegan JF. Ecology drives the worldwide distribution of human diseases. PLoS Biol. 2004;2:e141. https://doi.org/10. 1371/journal.pbio.0020141.

22. Nunn CL, Altizer SM, Sechrest W, Cunningham AA. Latitudinal gradients of parasite species richness in primates. Divers Distrib. 2005;11:249-56.

23. Bordes F, Guégan JF, Morand S. Microparasite species richness in rodents is higher at lower latitudes and is associated with reduced litter size. Oikos. 2011;120:1889-96.

24. Krasnov BR, Shenbrot Gl, Khokhlova IS, Degen AA. Flea species richness and parameters of host body, host geography and host 'milieu'. J Anim Ecol. 2004;73:1121-8.

25. Peng PY, Guo XG, Ren TG, Song WY, Dong WG, Fan R. Species diversity of ectoparasitic chigger mites (Acari: Prostigmata) on small mammals in Yunnan Province. China Parasitol Res. 2016;115:3605-18. https://doi.org/10. 1007/s00436-016-5127-X.

26. Peng PY, Guo XG, Jin DC, Dong WG, Qian TJ, Qin F, et al. Landscapes with different biodiversity influence distribution of small mammals and their ectoparasitic chigger mites: a comparative study from Southwest China. PLoS One. 2018;13:e0189987. https://doi.org/10.1371/journal.pone.0189987.

27. Park GM, Shin HS. Geographical distribution and seasonal indices of chigger mites on small mammals collected on the east coast of the Republic of Korea. J Parasitol. 2016;102:193-8. https://doi.org/10.1645/15-760.

28. Choi YJ, Lee IY, Song HJ, Kim J, Park HJ, Song D, et al. Geographical distribution of Orientia tsutsugamushi strains in chiggers from three provinces in Korea. Microbiol Immunol. 2018;62:547-53. https://doi.org/10. 1111/1348-0421.12639.

29. Kuo CC, Lee PL, Chen CH, Wang HC. Surveillance of potential hosts and vectors of scrub typhus in Taiwan. Parasit Vectors. 2015;8:611. https://doi. org/10.1186/s13071-015-1221-7.

30. Wardrop NA, Kuo CC, Wang HC, Clements AC, Lee PF, Atkinson PM. Bayesian spatial modelling and the significance of agricultural land use to scrub typhus infection in Taiwan. Geospat Health. 2013:8:229-39. https://doi. org/10.4081/gh.2013.69.

31. Tanskul P, Linthicum KJ. Redescription of Leptotrombidium (Leptotrombidium) imphalum (Acari: Trombiculidae), with observations on bionomics and medical importance in northern Thailand. J Med Entomol. 1999;36:88-91.

32. Rio RV, Attardo GM, Weiss BL. Grandeur alliances: Symbiont metabolic integration and obligate arthropod hematophagy. Trends Parasitol. 2016;32: 739-49. https://doi.org/10.1016/j.pt.2016.05.002.

33. Hansen AK, Moran NA. The impact of microbial symbionts on host plant utilization by herbivorous insects. Mol Ecol. 2014;23:1473-96. https://doi.org/ 10.1111/mec.12421.

34. Morand S, Bordes F, Chen HW, Claude J, Cosson JF, Galan M, et al. Global parasite and Rattus rodent invasions: the consequences for rodent-borne diseases. Integr Zool. 2015;10:409-23. https://doi.org/10. 1111/1749-4877.12143.

35. Blasdell K, Bordes F, Chaisiri K, Chaval Y, Claude J, Cosson JF, et al. Progress on research on rodents and rodent-borne zoonoses in South-east Asia. Wildl Res. 2015;42:98-107. https://doi.org/10.1071/WR14201.

36. Chaisiri K, McGarry JW, Morand S, Makepeace BL. Symbiosis in an overlooked microcosm: a systematic review of the bacterial flora of mites. Parasitology. 2015;142:1152-62. https://doi.org/10.1017/S0031182015000530.
37. Traub R, Wisseman CL Jr. Ecological considerations in scrub typhus. 2. Vector species. Bull World Health Organ. 1968;39:219-30.

38. Kwong WK, Moran NA. Cultivation and characterization of the gut symbionts of honey bees and bumble bees: description of Snodgrassella alvi gen. nov., sp. nov., a member of the family Neisseriaceae of the Betaproteobacteria, and Gilliamella apicola gen. nov., sp. nov., a member of Orbaceae fam. nov., Orbales ord. nov., a sister taxon to the order 'Enterobacteriales' of the Gammaproteobacteria. Int J Syst Evol Microbiol. 2013;63:2008-18. https://doi.org/10.1099/ijs.0.044875-0.

39. Wertz JT, Breznak JA. Stenoxybacter acetivorans gen. nov., sp. nov., an acetate-oxidizing obligate microaerophile among diverse O2-consuming bacteria from termite guts. Appl Environ Microbiol. 2007;73:6819-28. https:// doi.org/10.1128/AEM.00786-07.

40. Literak I, Stekolnikov AA, Sychra O, Dubska L, Taragelova V. Larvae of chigger mites Neotrombicula spp. (Acari: Trombiculidae) exhibited Borrelia but no Anaplasma infections: a field study including birds from the Czech Carpathians as hosts of chiggers. Exp Appl Acarol. 2008:44:307-14. https:// doi.org/10.1007/s10493-008-9150-1.

41. Kampen H, Scholer A, Metzen M, Oehme R, Hartelt K, Kimmig P, et al. Neotrombicula autumnalis (Acari, Trombiculidae) as a vector for Borrelia burgdorferi sensu lato? Exp Appl Acarol. 2004;33:93-102.

42. Zeigler DR. The Geobacillus paradox: why is a thermophilic bacterial genus so prevalent on a mesophilic planet? Microbiology. 2014;160:1-11. https:// doi.org/10.1099/mic.0.071696-0.

43. Hammer TJ, Dickerson JC, Fierer N. Evidence-based recommendations on storing and handling specimens for analyses of insect microbiota. PeerJ. 2015;3:e1190. https://doi.org/10.7717/peerj.1190.

44. Lawrence AL, Hii SF, Chong R, Webb CE, Traub R, Brown G, et al. Evaluation of the bacterial microbiome of two flea species using different DNAisolation techniques provides insights into flea host ecology. FEMS Microbiol Ecol. 2015;91. https://doi.org/10.1093/femsec/fiv134

45. Gemperline E, Horn HA, DeLaney K, Currie CR, Li L. Imaging with mass spectrometry of bacteria on the exoskeleton of fungus-growing ants. ACS Chem Biol. 2017;12:1980-5. https://doi.org/10.1021/acschembio.7b00038.

46. Kolberg R, Lawo NC, Forneck A. Investigation on maternal transmission of the bacteria Pantoea agglomerans by grape phylloxera (Daktulosphaira vitifoliae Fitch). Acta Hortic. 2011;904:41-5. https://doi.org/10.17660/ ActaHortic.2011.904.5.

47. Jousselin E, Clamens AL, Galan M, Bernard M, Maman S, Gschloessl B, et al. Assessment of a 165 rRNA amplicon Illumina sequencing procedure for studying the microbiome of a symbiont-rich aphid genus. Mol Ecol Resour. 2016;16:628-40. https://doi.org/10.1111/1755-0998.12478.

48. Seipke RF, Barke J, Heavens D, Yu DW, Hutchings MI. Analysis of the bacterial communities associated with two ant-plant symbioses. MicrobiologyOpen. 2013;2:276-83. https://doi.org/10.1002/mbo3.73.

49. McCarthy CB, Diambra LA, Rivera Pomar RV. Metagenomic analysis of taxa associated with Lutzomyia longipalpis, vector of visceral leishmaniasis, using an unbiased high-throughput approach. PLoS Negl Trop Dis. 2011;5:e1304. https://doi.org/10.1371/journal.pntd.0001304.

50. Segata N, Baldini F, Pompon J, Garrett WS, Truong DT, Dabire RK, et al. The reproductive tracts of two malaria vectors are populated by a core microbiome and by gender- and swarm-enriched microbial biomarkers. Sci Rep. 2016;6:24207. https://doi.org/10.1038/srep24207.

51. Gurfield N, Grewal S, Cua LS, Torres PJ, Kelley ST. Endosymbiont interference and microbial diversity of the Pacific coast tick, Dermacentor occidentalis, in San Diego County, California. Peer J. 2017;5:e3202. https://doi.org/10.7717/ peerj.3202.

52. Salter SJ, Cox MJ, Turek EM, Calus ST, Cookson WO, Moffatt MF, et al. Reagent and laboratory contamination can critically impact sequence-based microbiome analyses. BMC Biol. 2014;12:87. https://doi.org/10.1186/s12915014-0087-z

53. Glassing A, Dowd SE, Galandiuk S, Davis B, Chiodini RJ. Inherent bacterial DNA contamination of extraction and sequencing reagents may affect interpretation of microbiota in low bacterial biomass samples. Gut Pathog. 2016:8:24. https://doi.org/10.1186/s13099-016-0103-7.

54. Kennedy K, Hall MW, Lynch MD, Moreno-Hagelsieb G, Neufeld JD. Evaluating bias of Illumina-based bacterial 16S rRNA gene profiles. Appl Environ Microbiol. 2014;80:5717-22. https://doi.org/10.1128/AEM.01451-14.

55. Laursen MF, Dalgaard MD, Bahl MI. Genomic GC-content affects the accuracy of 165 rRNA gene sequencing based microbial profiling due to PCR bias. Front Microbiol. 2017;8:1934. https://doi.org/10.3389/fmicb.2017.01934. 
56. Traub R, Wisseman CL Jr. The ecology of chigger-borne rickettsiosis (scrub typhus). J Med Entomol. 1974;11:237-303.

57. Rozsa L, Reiczigel J, Majoros G. Quantifying parasites in samples of hosts. J Parasitol. 2000;86:228-32. https://doi.org/10.2307/3284760.

58. Auffray JC, Blasdell KR, Bordes F, Chabé M, Chaisiri K, Charbonnel N, et al. In: Herbreteau V, Jittapalapong S, Rerkamnuaychoke W, Chaval Y, Cosson JF, editors. Protocols for field and laboratory rodent studies. Bangkok: Kasetsart University Press; 2011.

59. Chaisiri K, Siribat P, Ribas A, Morand S. Potentially zoonotic helminthiases of murid rodents from the Indo-Chinese peninsula: impact of habitat and the risk of human infection. Vector Borne Zoonotic Dis. 2015;15:73-85. https:// doi.org/10.1089/vbz.2014.1619.

60. Oksanen J, Blanchet FG, Friendly M, Kindt R, Legendre P, McGlinn D, et al. vegan: Community Ecology Package. 2015. http://cran.r-project.org/ package=vegan Accessed: 24 Dec 2018.

61. Dormann CF, Fründ J, Blüthgen N, Gruber B. Indices, graphs and null models: analyzing bipartite ecological networks. Open Ecol J. 2009;2:7-24. https://doi.org/10.2174/1874213000902010007.

62. Opsahl T. tnet: Software for analysis of weighted, two-mode, and longitudinal networks. 2015. https://cran.r-project.org/package=tnet Accessed: 24 Dec 2018

63. Bates D, Machler M, Bolker BM, Walker SC. Fitting linear mixed-effects models using Ime4. J Stat Softw. 2015;67:1-48.

64. Calcagno V, de Mazancourt C. glmulti: An R package for easy automated model selection with (generalized) linear models. J Stat Softw. 2010;34:1-29.

65. Caporaso JG, Lauber CL, Walters WA, Berg-Lyons D, Lozupone CA, Turnbaugh PJ, et al. Global patterns of 16S rRNA diversity at a depth of millions of sequences per sample. Proc Natl Acad Sci U S A. 2011;108(Suppl 1):4516-22. https://doi.org/10.1073/pnas.1000080107.

66. Kozich JJ, Westcott SL, Baxter NT, Highlander SK, Schloss PD. Development of a dual-index sequencing strategy and curation pipeline for analyzing amplicon sequence data on the MiSeq Illumina sequencing platform. Appl Environ Microbiol. 2013;79:5112-20. https://doi.org/10.1128/AEM.01043-13.

67. Anonymous. 165 Metagenomic Sequencing Library Preparation: Illumina, Inc; 2013. p. 28. http://emea.support.illumina.com/downloads/16s metagenomic_sequencing_library_preparation.html?langsel=/gb/Accessed: 24 Dec 2018

68. Caporaso JG, Kuczynski J, Stombaugh J, Bittinger K, Bushman FD, Costello EK, et al. QIIME allows analysis of high-throughput community sequencing data. Nat Methods. 2010;7:335-6. https://doi.org/10.1038/nmeth.f.303.

69. Edgar RC. Search and clustering orders of magnitude faster than BLAST. Bioinformatics. 2010;26:2460-1. https://doi.org/10.1093/bioinformatics/btq461.

70. McDonald D, Price MN, Goodrich J, Nawrocki EP, DeSantis TZ, Probst A, et al. An improved Greengenes taxonomy with explicit ranks for ecological and evolutionary analyses of bacteria and archaea. ISME J. 2012;6:610-8. https://doi.org/10.1038/ismej.2011.139.

71. Haas BJ, Gevers D, Earl AM, Feldgarden M, Ward DV, Giannoukos G, et al. Chimeric 165 rRNA sequence formation and detection in Sanger and 454pyrosequenced PCR amplicons. Genome Res. 2011;21:494-504. https://doi. org/10.1101/gr.112730.110

72. Wang Q, Garrity GM, Tiedje JM, Cole JR. Naive Bayesian classifier for rapid assignment of rRNA sequences into the new bacterial taxonomy. Appl Environ Microbiol. 2007;73:5261-7. https://doi.org/10.1128/AEM.00062-07.

73. Soergel DA, Dey N, Knight R, Brenner SE. Selection of primers for optimal taxonomic classification of environmental $16 \mathrm{~S}$ rRNA gene sequences. ISME J. 2012;6:1440-4. https://doi.org/10.1038/ismej.2011.208.

74. Tamura K, Stecher G, Peterson D, Filipski A, Kumar S. MEGA6: molecular evolutionary genetics analysis version 6.0. Mol Biol Evol. 2013;30:2725-9. https://doi.org/10.1093/molbev/mst197.

75. Kibbe WA. OligoCalc: an online oligonucleotide properties calculator. Nucleic Acids Res. 2007;35:W43-6. https://doi.org/10.1093/nar/gkm234.

\section{Publisher's Note}

Springer Nature remains neutral with regard to jurisdictional claims in published maps and institutional affiliations.

\section{Ready to submit your research? Choose BMC and benefit from:}

- fast, convenient online submission

- thorough peer review by experienced researchers in your field

- rapid publication on acceptance

- support for research data, including large and complex data types

- gold Open Access which fosters wider collaboration and increased citations

- maximum visibility for your research: over $100 \mathrm{M}$ website views per year

At BMC, research is always in progress.

Learn more biomedcentral.com/submissions 